\title{
Reticular Chemistry: Molecular Precision in Infinite 2D and 3D*
}

\author{
Omar M. Yaghi
}

The long-standing dream of scientists to be able to link molecules together into crystalline, extended (infinite) 2D and 3D structures is now realized by the establishment of reticular chemistry through the discovery and development of metal-organic frameworks and covalent organic frameworks. The architectural, thermal, and chemical stability of such frameworks allowed study of their ultra-high porosity, reactivity and many applications including carbon capture and conversion to fuels, and water harvesting from desert air.

Keywords: Reticular; MOF; COF; Porosity; Water Harvesting; Carbon Dioxide; Molecular Weaving.

\section{SECTION 1: SUMMARY OF THE MAIN POINTS}

Reticular, from reticulum meaning 'netlike' structure, is commonly used in anatomy to describe the arrangements of fibrils, blood vessels, and cells. We introduced this term in the chemical literature to describe the chemistry of linking molecular building units into extended two- and three-dimensional ordered structures using strong bonds - reticular chemistry. In these structures, either organic and inorganic units are linked together by strong metal-ligand bonds to make metal-organic frameworks (MOFs), or organic units are linked together by strong covalent bonds to make covalent organic frameworks (COFs). Since the building units are multi-metallic clusters and large organic molecules, the resulting frameworks encompass space within which gases such as hydrogen, methane, and carbon dioxide can be stored and other molecules ranging in size from water to proteins incorporated. The fact that these frameworks are crystalline provides for their welldefined structure, and the strong bonds making up their backbone lead to robust structures of architectural, thermal and chemical stability.
To fully appreciate reticular chemistry, the MOF and COF structures should be conceptually divided into the backbone of the framework and the space being encompassed by that framework. The backbone can be designed from variously shaped molecules to create frameworks with desirable chemical composition, structure and pore metrics, and it can be chemically modified by covalent attachment of metal complexes or organic moieties to fashion the pores for specific functions. The rigidity of the backbone ensures precision in where and how far into the pores such functional units are placed, and therefore, it has become a commonplace in reticular chemistry to make-to-order structures suitable for catalysis, removal of contaminants, storage of fuel gases, or harvesting water from desert air, to mention a few functions. There are two important features of reticular chemistry: First, the size of the constituent building units in a framework can be expanded or contracted, and as long as its connectivity is not altered, the resulting framework will have expanded or contracted dimensions. Second, for a given framework, such constituents can also be chemically functionalized either pre- or post-synthetically, while

Department of Chemistry, University of California, Berkeley, CA 94720, USA, yaghi@berkeley.edu. Published online 12 April 2019; doi:10.1142/ S2529732519400054

*This article covers my presentation at the Molecular Frontiers Conference, Stockholm 2019.

This is an Open Access article published by World Scientific Publishing Company. It is distributed under the terms of the Creative Commons Attribution 4.0 (CC-BY) License. Further distribution of this work is permitted, provided the original work is properly cited. 
maintaining the framework's connectivity, to produce functionalized pores.

The process of modifying frameworks without altering their underlying connectivity, as just described, yields isoreticular frameworks (frameworks of the same connectivity/topology). This has become known as the 'isoreticular principle' and it has enabled synthesis of MOFs and COFs by design, and led to frameworks of vastly varied pore sizes and functionalities. One outcome of this diversity has been the ability to make a framework whose pores are functionalized with more than one kind of functional group. Thus, the backbone of such a framework is a repeat of a few kind of building units onto which multiple functionalities are covalently attached. This aspect is conceptually related to DNA: the polyphosphate sugar backbone is a repeat of few kind of building units onto which the nucleotides are covalently attached to give unique sequences capable of coding for protein synthesis. This analogy, although rudimentary, gives rise to the notion that such $\mathrm{MOF}$ and COF structures of multivariate nature may very well allow for the design of sequences of functionalities to code for specific properties. Preliminary evidence show that multivariate MOFs perform much better than the sum of their parts, clearly pointing to the collective power of having multiple functionalities in the pores of reticular frameworks.

On the fundamental level, reticular chemistry allows us to relate the framework to the molecule as we would relate the molecule to the atom: The molecule fixes the atom in specific connectivity, geometry, and spatial arrangement, while the framework fixes the molecule in specific connectivity, geometry, and spatial arrangement. However, unlike the molecule, the framework encompasses space within which matter can be further manipulated and controlled. Indeed, the precision in building reticular frameworks and chemically modifying them, without losing their crystallinity or porosity, brings to reality the idea of working with 'crystals as molecules'. In essence, reticular chemistry ushers a new era of chemistry where molecular design and precision is extended to $2 \mathrm{D}$ and $3 \mathrm{D}$ using metal-organic and organic frameworks.

In this contribution, the incipient stage of reticular chemistry, the early discoveries leading to its development, the specific parameters and principles governing its practice, and the vast opportunities it provides in the larger context of chemistry for advancing the basic chemical sciences and creating new solutions to vexing societal problems are presented and discussed.

\section{SECTION 2: HISTORICAL PERSPECTIVE AND DISCOVERY OF MOFs AND COFs}

Historical Perspectives: Two major scientists figure prominently in the history preceding reticular chemistry. The first is Alfred Werner, the founder of coordination

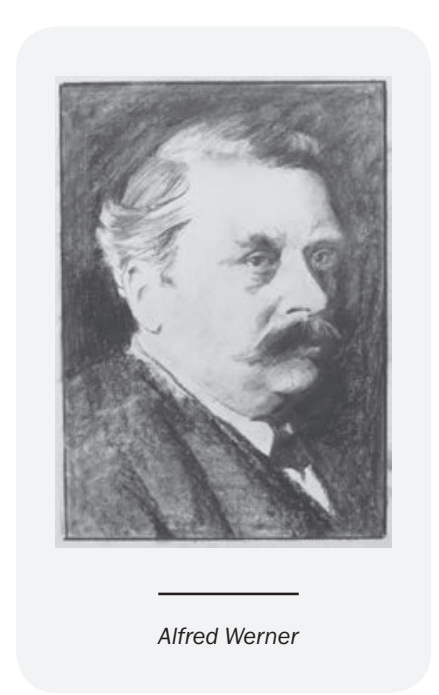

chemistry whose work led to the correct geometry and connectivity in which metal ions and ligands form complexes. He discovered that for some complexes such as $\beta$ - $\mathrm{Co}(4-$ methylpyridine $)_{4}(\mathrm{NCS})_{2}$, solvent molecules (e.g. benzene) reside within their molecular crystals $^{1}$. Almost fifty years later, it was found that these molecules, termed guests, can be evacuated from the crystals leaving behind space, which can be filled with gases such as nitrogen and carbon dioxide ${ }^{2}$. It was observed then that upon cycling gases in and out of the crystals, the molecular complexes reoriented themselves to fill that space, thereby rendering the crystals non-porous. It would have been natural to imagine the need for linking such metal complexes into extended networks, and that if these networks are architecturally robust, they would impart permanent porosity. The literature became replete with examples were metal ions are joined by organic linkers to yield noncrystalline 'coordination polymers' whose structures were difficult to characterize ${ }^{3}$.

The first examples of crystalline coordination networks were reported in 1959 and many more of this genre followed ${ }^{4,5}$. Since the linkages within these networks are based on the weak M-(neutral ligand) bonding such as $\mathrm{Cu}(\mathrm{l})$ bound by nitrile- and pyridine-type organic linkers, their structures were too frail to support porosity, and have low thermal and chemical stability, thus precluding their use as porous compounds ${ }^{6-10}$. It might be noted in passing that metal cyanides such as Prussian blue compounds and Hofmann clathrates, although based on the strong $\mathrm{M}$-(charged ligand) bonding and therefore could support porosity, they are severely limited by the non-functionalized nature of the cyanide linker ${ }^{11,12}$.

This state-of-affairs continued until 1998, when the synthesis, crystal structure, and porosity of a zinc-terephthalate compound, termed metal-organic framework-2 (MOF-2), were reported ${ }^{13}$. It is composed of the well-known paddlewheel di-zinc units linked to terephthalate to make a 2D framework with $10 \AA$-diameter channels (Fig.1a). Removal of the N,N-dimethylformamide guests filling the pores, and measurement of nitrogen adsorption isotherms showed a Type I behavior, evidence of permanently porous structure (Fig. 1b). These isotherms, measured at $77 \mathrm{~K}$ and low pressure, are the gold standard for measuring porosity since it is only from this data (not high pressure, room temperature 


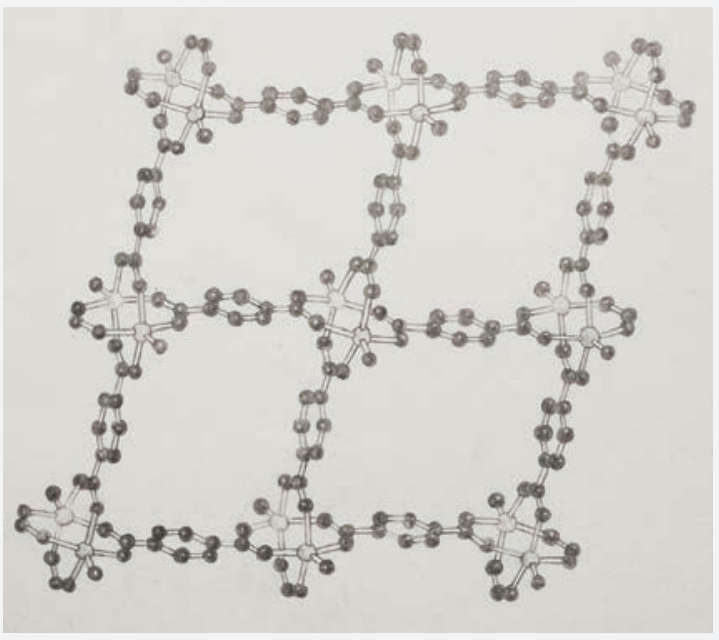

Fig. 1a. Crystal structure of metal-organic framework-2 (MOF-2), Zn(terephthalate). Zinc ions (light gray spheres) are linked by terephthalate into extended $2 D$ porous structure. (Spheres terminal to zinc are oxygens from water ligands).

data) that the pore-volume and surface area of a porous structure can be obtained. It is important to note that the gas adsorption measurements of MOF-2 were the first to be performed for any extended metal-organic structure. MOF-2 was found to have a pore volume of $0.17 \mathrm{~cm}^{3} / \mathrm{cm}^{3}$ and a surface area of $375 \mathrm{~m}^{2} / \mathrm{g}$.

A similar strategy was applied in the synthesis of the now iconic-MOF-5 whose structure is composed of

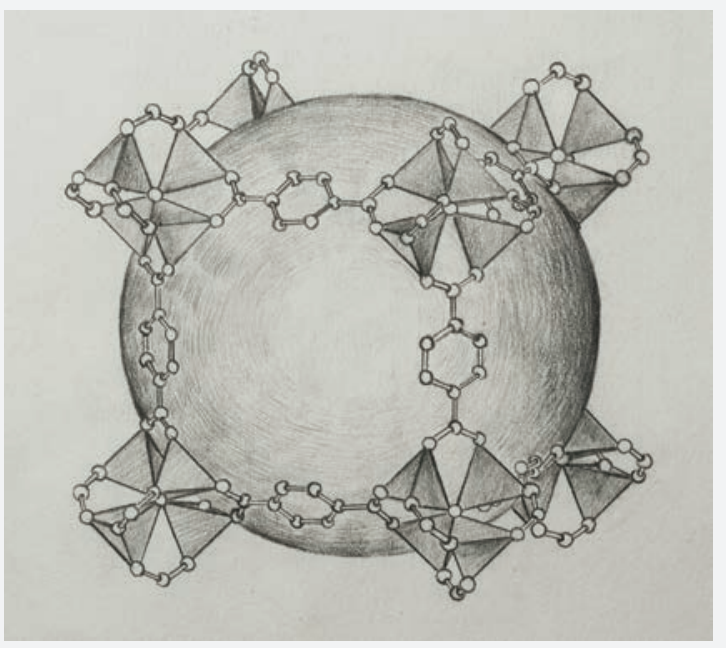

Fig. 2a. The crystal structure of MOF-5 showing $\mathrm{Zn}_{4} \mathrm{O}$ units (corners) linked by terephthalate to make extended $3 D$ structure. The Ball indicates the smallest sphere to fit the pore without touching the van der Waals radii of framework atoms.

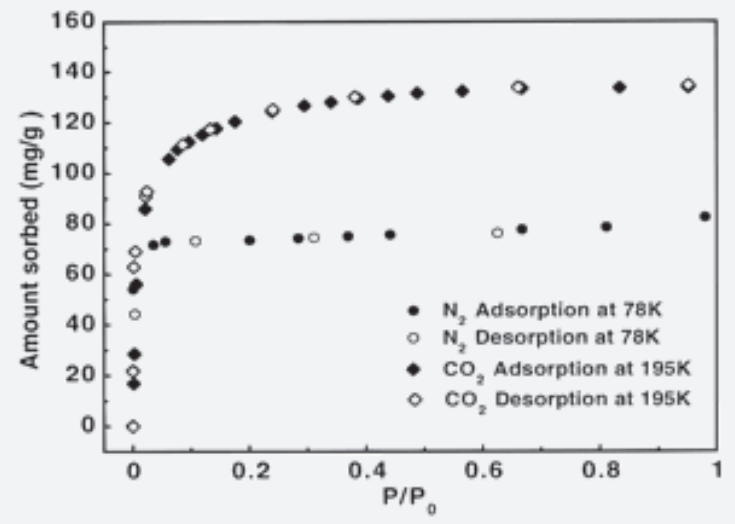

Fig. 1b. $\mathrm{N}_{2}$ adsorption isotherm of MOF-2 proving its permanent porosity. The $\mathrm{CO}_{2}$ isotherm is also shown. These isotherms constitute the first proof of porosity in MOFs. From this data porosity values can be obtained.

tetra-zinc oxide units linked by terephthalate to make $\mathrm{Zn}_{4} \mathrm{O}$ (terephthalate) ${ }_{3}$ compound ${ }^{14}$. The crystal structure of this compound is a primitive cubic extended 3D framework (Fig. 2a). Extensive gas and liquid adsorption measurements were performed on the evacuated form of MOF-5 and from the nitrogen adsorption isotherm the pore volume was determined to be $0.60 \mathrm{~cm}^{3} / \mathrm{cm}^{3}$ and the surface area found to be $2900 \mathrm{~m}^{2} / \mathrm{g}$ (Fig. 2b). These values far exceeded the records held by the traditional porous crystalline zeolites and amorphous carbon. The new record of porosity for MOF- 5 raised a lot of excitement in the science community. A crystal structure of fully evacuated MOF- 5 crystals was successfully obtained

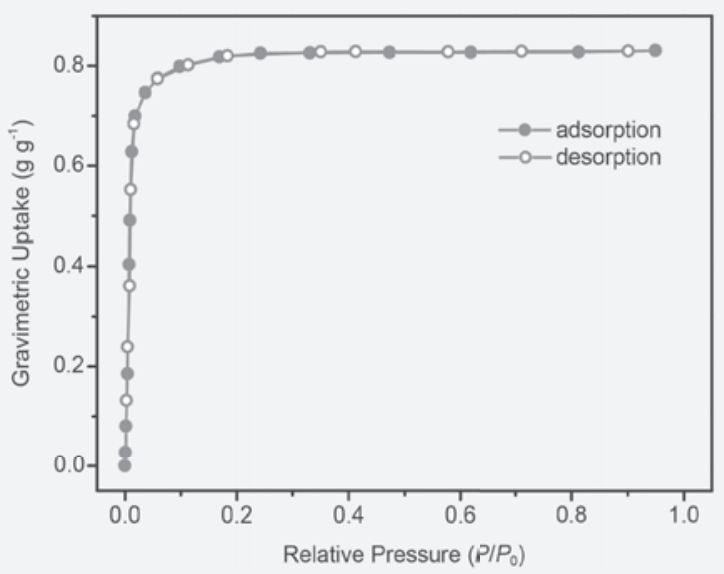

Fig. $2 b . \mathrm{N}_{2}$ adsorption isotherm of MOF-5 (77 K) revealing its ultrahigh porosity. 
as additional direct evidence of its architectural stability in the absence of guests ${ }^{15,16}$

MOF-2 and MOF-5 played a pivotal role in establishing the principles of building permanently porous MOFs. The metal-(carboxylate) bonds are much stronger than those of the traditional coordination networks due to the charge imparted by the carboxylate, and this strength leads to robust frameworks that sustain permanent porosity. The fact that the carboxylate units chelate to the metal ions allows for the formation of di- and multi-metallic clusters (termed secondary building units, SBUs), which serve as anchors to further stabilize the MOF structure. This is in contrast to the single metal-ion nodes present in coordination networks that lead to 'wobbly' and unsteady structures. The success in building MOF-2 and MOF-5 also meant that one can link organic and inorganic units through strong bonds to make porous structures whose constituents can be potentially varied and modified using established molecular chemistry reactions as described further below ${ }^{17}$.

The second ma-

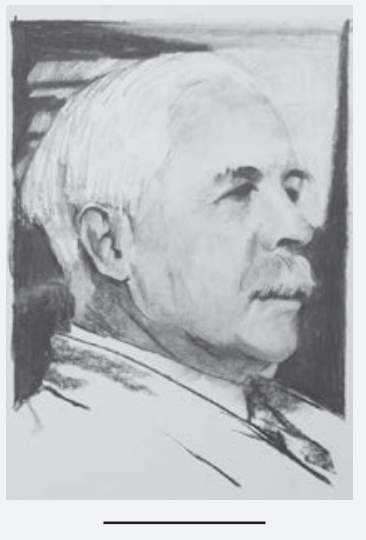

Gilbert N. Lewis jor scientist is Gilbert N. Lewis whose ideas on linking atoms to molecules laid the foundations for what became known as the covalent bond ${ }^{18}$. The covalent bond has been at the center of major developments in organic chemistry most especially total synthesis of large, complex organic molecules, polymers, and dendrimers. However, the development of the analogous chemistry to make 2D and 3D extended structures remained largely undeveloped throughout the twentieth century. A statement published in 1993 by Roald Hoffmann describes the state of this science at that time ${ }^{19}$. He wrote: "Organic chemists are masterful at exercising control in zero dimension. One subculture of organic chemists has learned to exercise control in one dimension. These are polymer chemists, the chain builders... But in two or three dimensions, it is a synthetic wasteland."

This continued to be the case until we reported in 2005 the successful synthesis, crystallization, and porosity of $2 \mathrm{D} \mathrm{COFs}$, and in 2007 the extension of this strategy to $3 \mathrm{D} \mathrm{COFs}{ }^{20,21}$. These are based on linking symmetric organic molecules by boroxine and boronic ester linkages. The same Lewis dot structures that we commonly use to represent atoms and molecules now also apply to these COFs. It is useful to note that in MOFs the multi-metallic units form in situ, but in COF synthesis the organic building units maintain their original shape throughout the reaction with only the linkages joining the building units being new. Thus, by knowing the geometry of the building units and the linkages expected to form, it is a straight forward matter to predict the structures of $\mathrm{COFs}$ and make them by design.

\section{Discovery of Crystallization Conditions for MOFs and} COFs: It had been an article of faith that linking molecular building units by strong bonds would yield amorphous solids. In fact, as a student working in molecular chemistry, I experienced what every synthetic chemist must have done before me: when their reactions has gone awry, an intractable solid appeared at the bottom of the reaction vessel. We were routinely told to "throw it away" because there was no way to re-dissolve and crystallize it as molecular chemists would generally do. This is the same result that was obtained when attempts were made to deliberately link molecular building units by strong bonds. We used vapor diffusion methods to crystallize MOF-2 with very slow diffusion of base into the reaction mixture. The real and general breakthrough in crystallization of MOFs came when we employed $\mathrm{N}, \mathrm{N}$-dimethylformamide as a solvent in the reaction of zinc (II) nitrate with terephthalic acid to make MOF- 5 . As the solvent is heated, it releases dimethylamine, which as a base proceeds to deprotonate the terephthalic acid and cause a reaction with zinc (II) ions. Thus, the kinetics of crystallization can be precisely controlled by the rate of base release into the reaction mixture. This provided the handle needed to obtain crystals of MOF-5. The reaction conditions used to make MOF-5 or closely related conditions are still used in the synthesis of MOFs and have resulted in tens of thousands of new MOFs ${ }^{22}$.

Cognizant of the fact that microscopic reversibility will also be critical in the crystallization of COFs, we embarked on attempting to carry out the trimerization of phenylene di-boronic acid to produce a $2 \mathrm{D}$ framework with a structure based on that of graphite net topology ${ }^{20}$. The reactions were carried out in a sealed tube at $120^{\circ} \mathrm{C}$ in a solvent mixture of mesitylene and dioxane. These reactions gave amorphous, intractable solids. We discovered evidence of crystallinity as we varied the space above the reaction mixture in the tube. We reasoned that since water is a byproduct of this reaction, the resulting pressure of water in the tube might be modulating the crystallinity of the product through Le Chatelier's principle. Indeed, this led us to optimize the pressure of water and the proportion of solvents used to maintain the necessary balance between a reaction rate that is fast enough to allow a complete reaction and also provide sufficient time for selfcorrection to take place during crystal growth. These reaction conditions or closely related ones continue to be practiced today and have resulted in hundreds of new crystalline COF structures. 
In the remainder of this contribution, the development of MOFs and COFs are described in separate sections.

\section{SECTION 3A: THE STRUCTURE, POROSITY AND REACTIVITY OF METAL-ORGANIC FRAMEWORKS}

Having discovered the underpinning of making architecturally robust MOFs and crystallizing them, it was natural to extend reticular chemistry to other inorganic multi-metallic and organic building units to make a large number of different MOFs leading to what can only be described as a revolution in making new structures and materials.

Building Units as Nodes and Linkers: A library of discrete and infinite rod-shaped multi-metallic units, we termed secondary building units (SBUs), form when metal ions are joined by carboxylate-based organic linkers. The SBUs serve as anchors and the organic linkers as struts to produce robust MOFs. The resulting MOFs can be simplified by classifying a node as a junction (inorganic or organic) linking more than two building units, and a linker as 2-connected bridge (usually organic) between those units. The node and linker approach for reducing a crystal structure to its underlying net topology was outlined years ago for inorganic solids by A. F. Wells ${ }^{23}$. The application of this approach to MOFs and COFs allows us a simple way to classify and plan the synthesis of frameworks based on specific topologies ${ }^{24,25}$. The topology is denoted with three letter symbol in bold lower case. Thus, the grammar of design and taxonomy of such reticular frameworks played an important role in the wider applicability of reticular chemistry and in establishing it as a branch of chemistry.

\section{MOF Structures and the Origin of their Ultra-High Poros-}

ity: Among the many structures that could result from linking molecular shapes, which ones will result from reticular synthesis? Our thesis has been that reticular synthesis is likely to result in MOFs whose structures can be reduced to topologies based on the most symmetric nets especially when highly symmetric building units are used ${ }^{26}$. Indeed, this holds true for the large majority of MOFs. Based on this, the vast structure space of possible MOFs can belong to a relatively small number of nets (about 50) each of which potentially can be made from a large number of compositions. MOFs were made from triangles, tetrahedra, squares, octahedra, and a combination of some of these, including those with rod-shaped SBUs $^{17,22}$.

An important feature of MOF structures is that they have pores without walls. They are scaffold-like and this property allows for maximization of their internal surface area. In an experiment where small doses of nitrogen and argon were introduced in evacuated crystals of MOF- 5 whose single crystal X-ray diffraction data was collected at $20 \mathrm{~K}$, we observed that these gases bind to several sites on the SBU and on the faces and edges of the phenylene units ${ }^{16}$. In other words, MOF structures are replete with binding sites and thus have ultra-high surface area, making them ideal for gas storage and gas separation applications. MOFs with surface areas of over $7000 \mathrm{~m}^{2} / \mathrm{g}$ have been reported based on the strategy of including more phenylene and acetylenic units in the linker to allow for maximization of gas adsorptive sites ${ }^{22}$.

Isoreticular Principle: Once the reaction conditions and the crystallization parameters are figured out for making a MOF from a specific SBU and organic linker, those same conditions or closely related ones, are used to employ other linkers of the same connectivity but with different functionality and size. In this way, it was possible to make an isoreticular MOF- 5 series where the pores are functionalized and expanded (Fig. 3a) ${ }^{27}$. Members of this series were found to be self-interpenetrating but by using more dilute reaction conditions the non-interpenetrating forms can also be isolated and characterized. The isoreticular principle was also used to make a series of MOF-74 structures where the linker length ranged from one to eleven phenylene units (Fig. 3b). These isoreticular MOFs do not interpenetrate because the parent MOF-74 structure is based on a rod-like SBU and a topology where interpenetration is forbidden. We showed how members of this series take up very large clusters, enzymes, and proteins ${ }^{28}$.

Post-Synthetic Modifications: Once the MOF structure is isolated, the pores can be evacuated to remove solvent molecules incorporated during the synthesis. The evacuated MOF is then subjected to chemical reactions to modify the pore environment. Several useful strategies have been reported: (1) Open metal sites are produced in the pores by thermal removal of a terminal ligand dangling from a metal in an $\mathrm{SBU}^{29}$. These sites are useful in the selective separation of gases, Lewis-acid catalysis, and in binding metal complexes into the pores. (2) Metal-ion exchange in the SBU to produce a heterometallic SBU for exploitation of their catalytic activity ${ }^{30}$. It is also possible to exchange the organic linker with another bearing a new functional group. Substitution of organic linkers by terminal ligands yields defective MOFs ${ }^{31}$. (3) Post-synthetic covalent functionalization of the organic linker to introduce functionalities ${ }^{32}$ designed for the selective capture of specific substrates and gases. Such post-synthetic modifications are reported to maintain the crystallinity and porosity of the MOF. Thus, the precision of molecular chemistry can be applied to crystalline extended solids of MOFs and this brings to reality the long-standing idea of using 'crystals as molecules'33.

\section{SECTION 3B: SELECTED APPLICATIONS OF METAL-ORGANIC FRAMEWORKS}

MOFs are made in milligram to gram quantities in academic laboratories but our collaboration with industry has shown 


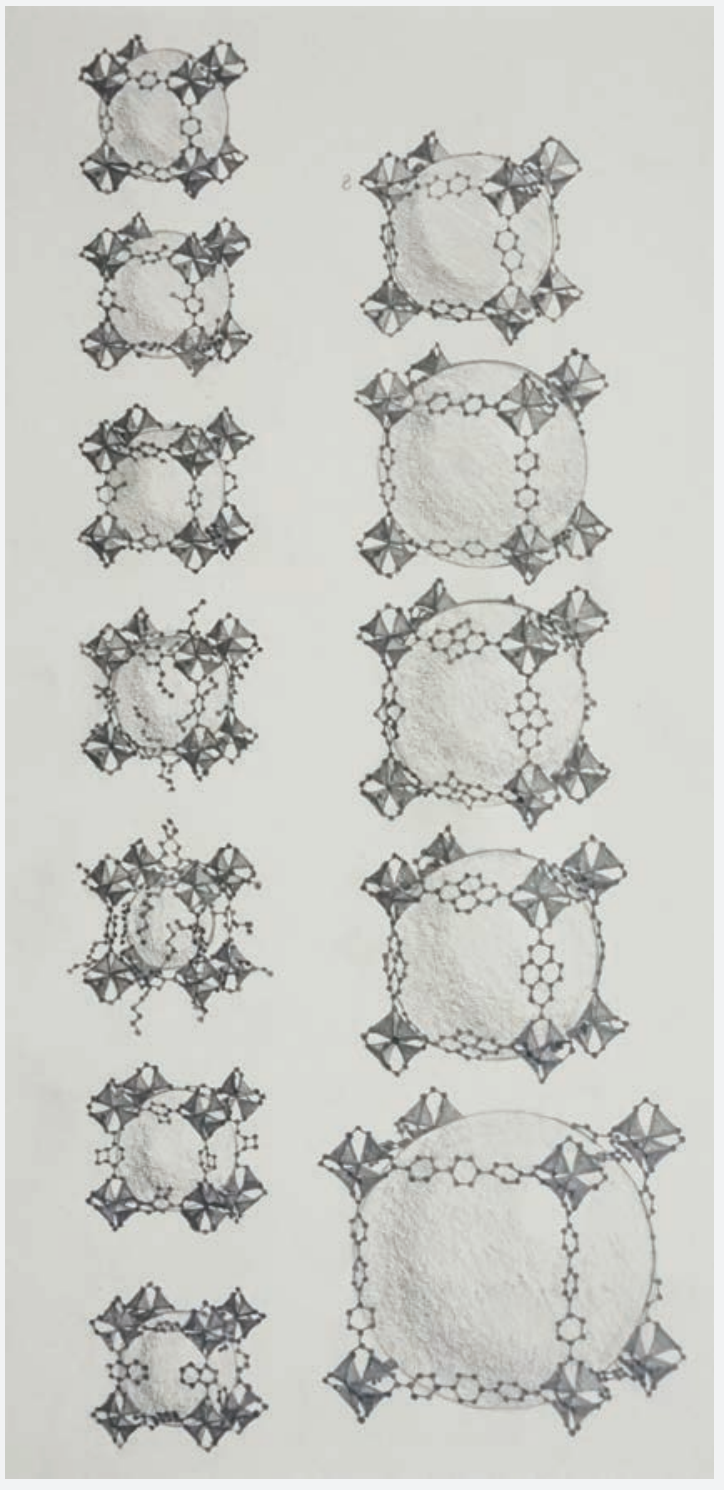

Fig. 3a. Isoreticular series of MOF-5 showing how the pores are functionalized and expanded.

that their synthesis is scalable to multi-ton quantities ${ }^{34}$. The availability of MOFs and the flexibility with which their structures can be varied and precisely modified lend itself well to exploitation of their applications. A wide-range of applications have already been reported including gas storage and separations, catalysis, conversion of gases for clean energy, optoelectronics, bio-imaging, and cancer therapeutics, to mention a few. In this section, two important societal problems are addressed by MOFs. Namely, carbon capture and harvesting water from desert air.

Carbon Dioxide Capture: Since the beginning of the industrial revolution, combustion of fossil fuels has resulted in almost

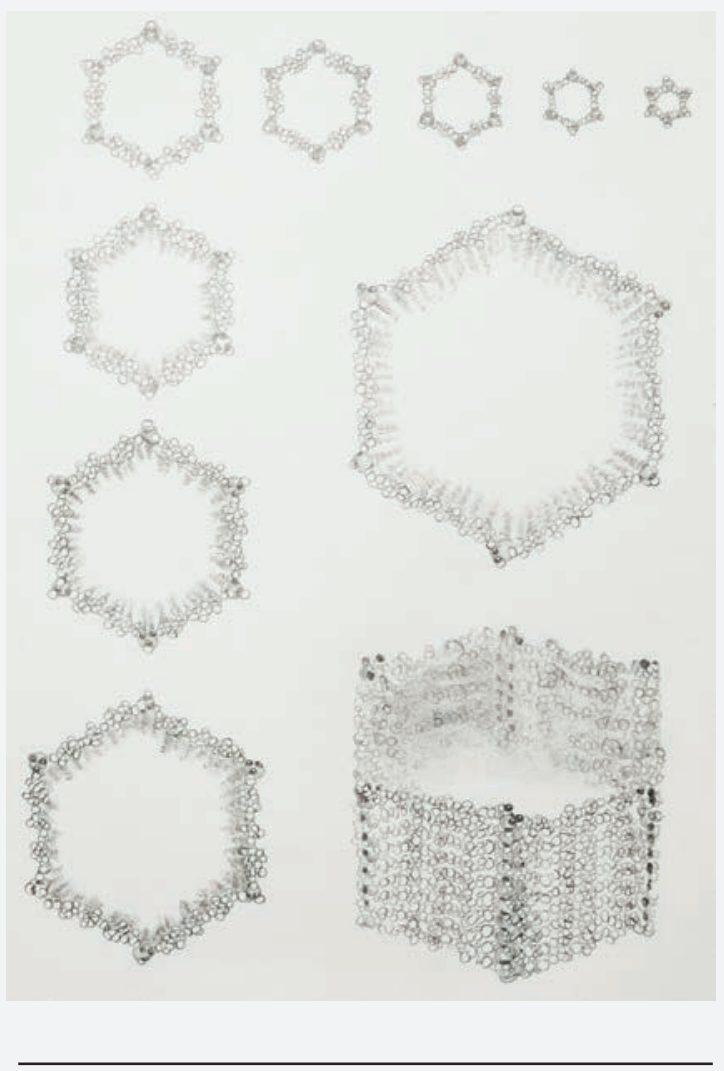

Fig. 3b. Isoreticular series of MOF-74 showing progressively larger pore opening.

doubling of carbon dioxide levels (400 ppm) in the atmosphere. A person living today is breathing nearly double the amount of carbon dioxide compared to one living one hundred years ago. To put it more directly, carbon dioxide emission annually is over 20 tons per capita worldwide. This massive amount of carbon dioxide is changing our environment irreversibly. The impact is visible in the damaged coral reefs due to increased acidity of the oceans, the rapid melting of ice caps due to global warming, and the rise of water in oceans endangering coastal cities most evidenced in major cities such as New York, Miami, Tokyo, Shanghai, and London. World society is 'addicted' to burning of fossil fuels and the collective will of nations to limit this activity is present but meaningful action on this vexing societal issue remains as yet absent.

Scientifically, the problem of capturing carbon dioxide from flue gas of power plants and other point sources is also challenging because of the need to selectively separate carbon dioxide from other gases and most especially water. One solution being contemplated and pursued is to use aqueous mono-ethanolamine solutions as a medium for capturing carbon dioxide. This is a technology long used for separating carbon dioxide from methane in the mining of natural gas. However, it is energetically costly because the formation of 
carbamides when carbon dioxide is absorbed requires heating to $120^{\circ} \mathrm{C}$ to remove the carbon dioxide and regenerate the amine solutions. If this is deployed in power plants, it will cost up to $40 \%$ of the energy output of a power plant. The high heat capacity of water in the amine solutions is the principal factor playing in this high energy penalty. In addition, the safety and environmental hazards created by using amine solutions, which degrade upon long-term cycling, further exacerbate the problem.

We believe that MOFs can overcome many of these shortcomings. Our strategy is to covalently functionalize the interior of the MOF with primary amines, which are ideally suited for capture of carbon dioxide even in the presence of water $^{35}$. Earlier studies showed that although MOFs take up voluminous amounts of carbon dioxide, the presence of water reduces their efficiency because water competes very effectively for the binding sites within the MOF. This problem was solved by introducing the primary amines within the pores of MOFs, where carbon dioxide is captured from a mixture of nitrogen and water and thermally cycled with significant improvements over the traditional aqueous mono-ethanolamine solutions. Breakthrough experiments clearly showed that from a mixture of nitrogen, water, and carbon dioxide, carbon dioxide can be held into the pores of isoreticular MOF74 , which was covalently functionalized with primary amines (Fig. 4) 36,37 .

Another solution to solving the challenge of competition between water and carbon dioxide for the binding sites of MOFs is to create hydrophobic structures as we have done with zeolitic imidazolate frameworks. We showed that when the pores within such structures are hydrophobic, they can exclude water while allowing carbon dioxide within the pores to reside and accumulate as in a reservoi ${ }^{38}$. Thus, the challenge

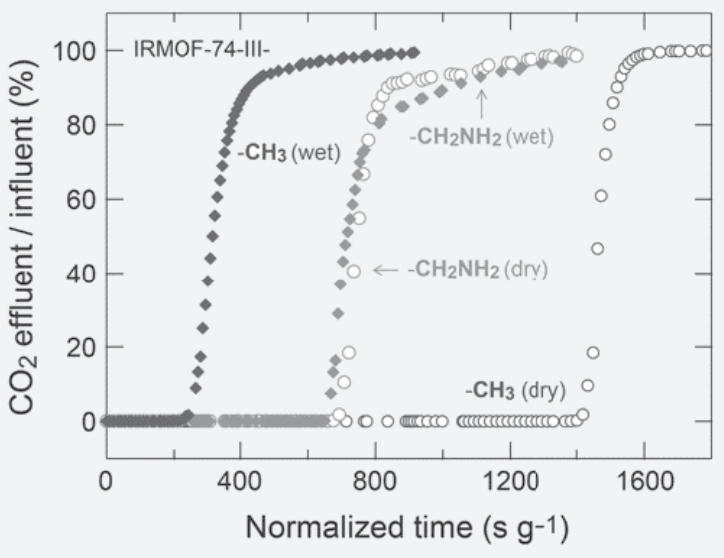

Fig. 4. Breakthrough results for selective capture of $\mathrm{CO}_{2}$ showing the separation of $\mathrm{CO}_{2}$ and from water. of capturing carbon dioxide selectively is solved, and what remains is optimization of capacity and eventually societal acceptance of the necessity for carbon dioxide capture.

Water Harvesting from Desert Air: Water is essential to life, yet increasingly it is becoming a scarce resource due to drought and pollution. There are communities in Africa and India whose members suffer death for either lack of water or clean water. In parts of northern India, farmers touch water drops to their tongue to avoid dehydration but they rarely can take a gulp of water. Almost one-third of the world population lives in water stressed regions. This is projected to increase to over half of the world population by the year 2050. A potential solution to water scarcity is to find ways of harvesting water from the atmosphere, where at any one time there is nearly as much water as in rivers and lakes on earth. The scientific challenge is how to harvest water from low humidity (5-40\% relative humidity) atmosphere such as commonly found in arid regions of the world. Although some zeolites can take up water into their pores from the atmosphere, removing it requires high temperature $\left(300^{\circ} \mathrm{C}\right)$, making it energy intensive process and therefore not viable as a water harvesting material.

We discovered, while studying carbon dioxide separation from water, a zirconium (IV) fumarate MOF (MOF-801) capable of taking up water at relative humidity of $20 \%$ and releasing it at $45^{\circ} \mathrm{C} \mathrm{(Fig.} 5 \mathrm{a}$ and b). We imagined that such a MOF can be deployed in the desert where at night it takes up water from the atmosphere, and during the day releases it as the temperature rises ${ }^{39}$. Indeed, we and collaborators designed a palm-sized device equipped with about 2 grams

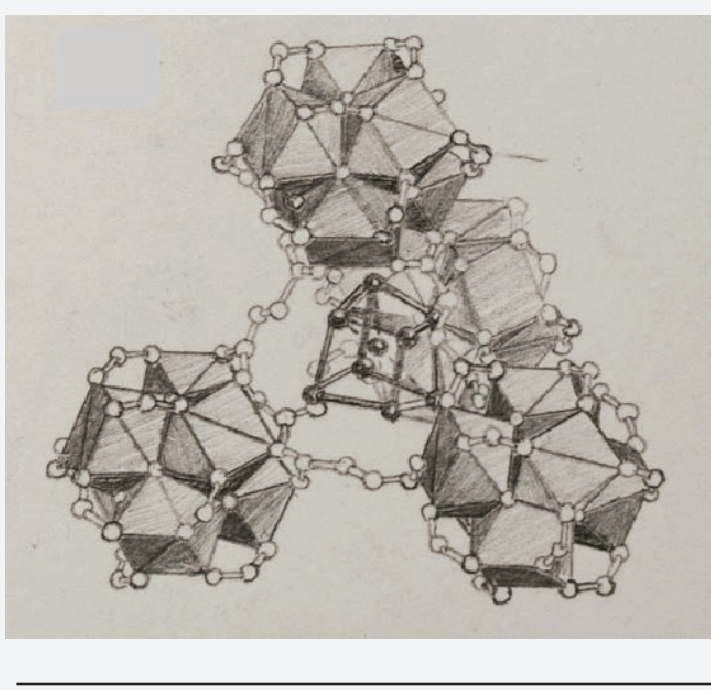

Fig. 5a. Crystal structure of MOF-801 with a cube of 8 water molecules shown in the pores that act as seeds for further uptake of water from air. 


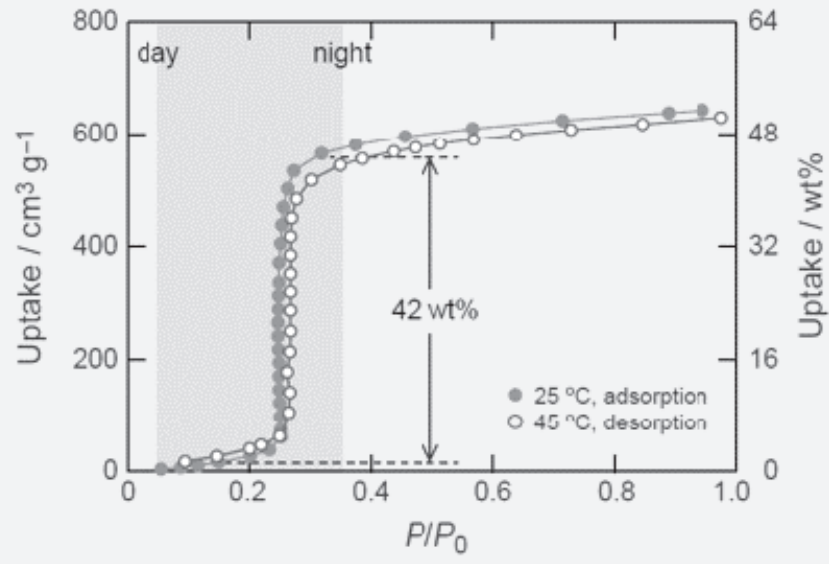

Fig. 5b. MOF-801 uptake of water under desert-like conditions.

of MOF-801 and tested it outside the laboratory and observed the formation of droplets coming out of the MOF film ${ }^{40}$. This observation was repeated successfully in the Arizona desert ${ }^{41}$. Although, no water was collected from these experiments, the observation of droplets growing as the MOF was being heated by sunlight was truly inspiring.
A second generation device was configured to have a box within a box, where the inner box was fitted with $1 \mathrm{~kg}$ of MOF-801 (Fig. 6) ${ }^{42}$. At night the outer box is opened to allow water from the atmosphere to fill the pores of the MOF residing in the inner box. At dawn the outer box is then closed and as sunlight shines on the device, the interior is heated and water released from the MOF. Since the interior is much hotter than the exterior of the device, water condenses on the inner walls of the outer box and water is collected. The device was successfully tested in the Arizona desert and found to deliver nearly 1 liter per kilogram per day, with no energy input aside from ambient sunlight. This represents the first demonstration of practical water harvesting from desert air. The fact that the MOF is scalable and that the box device is simple and made from inexpensive plexiglass material bodes well for its wide-spread use. Given the rapid kinetics of uptake and release and the facility of connecting this to solar panels, it is possible to run this device over 10 cycles per day. Unlike any other device or strategy reported to date, our MOFs work at low humidity and therefore create water where there is no water, and they do so in an energy efficient and practical

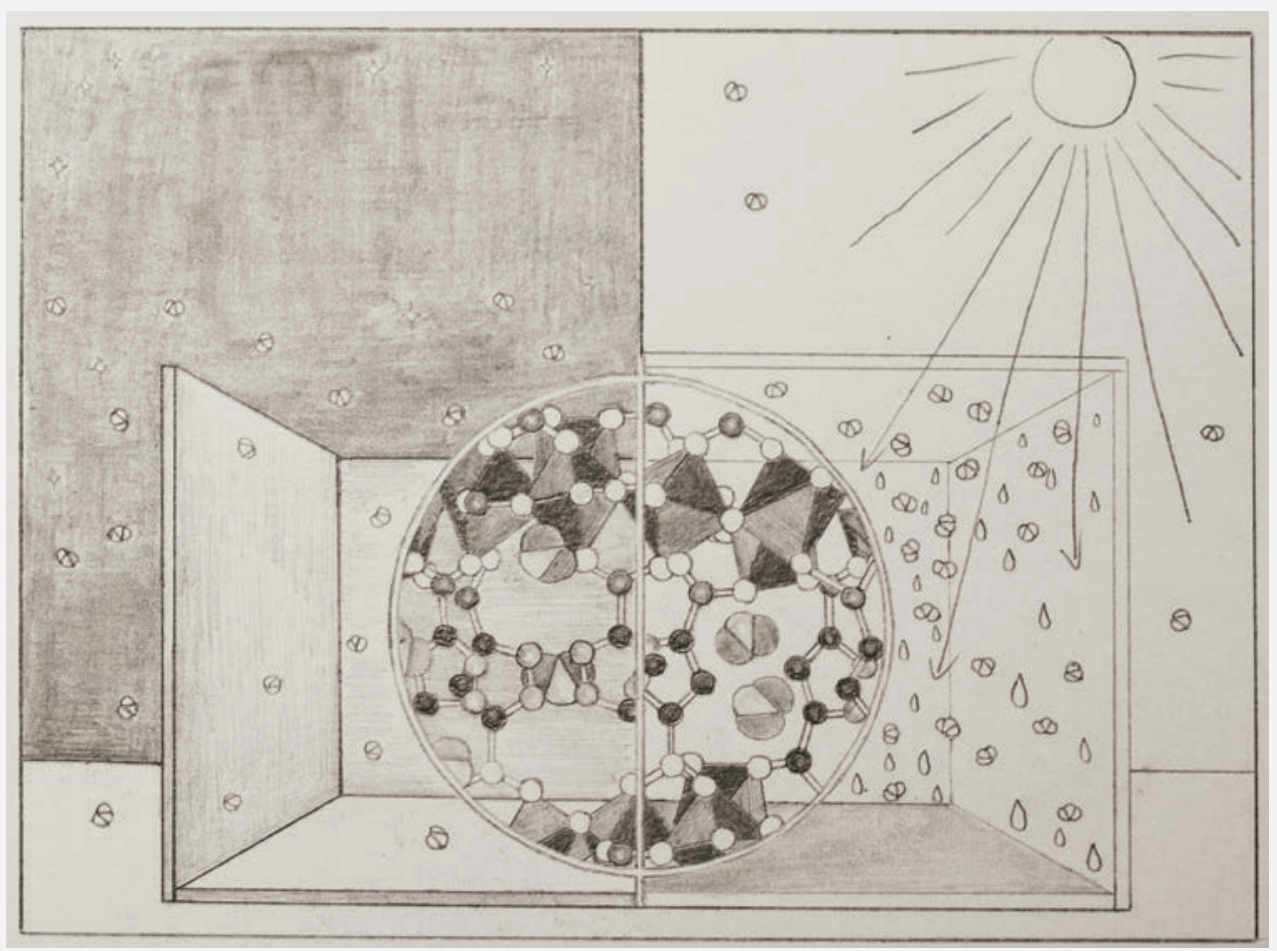

Fig. 6. MOF water harvesting device. Water enters the MOF at night (left side), and during the day sunlight heats the MOF resulting in release of water and its condensation (right side). 


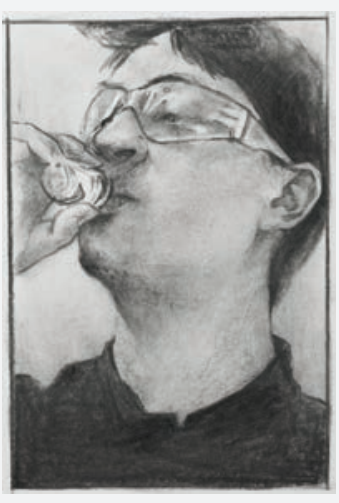

Dr. Eugene Kapustin drinking the harvested water. manner. This is quite a powerful result as it is a solution for watering arid regions of the water. The water harvested was tested for contaminants and found to be ultrapure with no detectable levels of metals ions or organics even after 150 cycles.

A closer examination of the behavior of water molecules in the pores of MOF-801, using single crystal neutron and X-ray diffraction studies, reveals that the first water molecules assemble into hydrogen-bonded tetrahedral, octahedral, face centered cubic, and body centered cubic arrangements before further water molecules come in to bind to these geometric 'seeds'. This observation explains the cooperative behavior unveiled by the water adsorption isotherms ${ }^{39}$. Based on these results, it has been possible to design MOFs capable of harvesting water from relative humidity levels as low as $7 \%$. We have already launched an effort to bring this progress to commercialization. Our vision is to make water available off-grid, personalized, and mobile.

\section{SECTION 4: COVALENT ORGANIC FRAMEWORKS}

The discovery of COFs has overturned the long-held belief that crystallization of 2D and 3D extended organic structures, linked by strong bonds, would be extremely difficult if not impossible. The chemistry of COFs relies almost entirely on the linkage between the building units. When these linkages are chosen to promote microscopic reversibility, we find that their crystallization, although challenging, is possible. However, this linkage property also impacts the chemical stability of the framework. The more reversible the linkages are, the more unlikely they will be chemically robust. We show in this section that frameworks from progressively less reversible linkages can be made as crystalline solids and that for those least reversible to irreversible linkages, we have developed post-synthetic linkage conversions to transform a reversible linkage to an irreversible one while still maintaining crystallinity and porosity of the framework. And in so doing, COFs of high thermal and chemical stability have become available.

Design of COFs: Just as for the SBUs of MOFs, the large size of the starting molecular units of COFs provides the rigidity necessary for architectural stability of the framework. A wide range of linkages have been successfully used and the

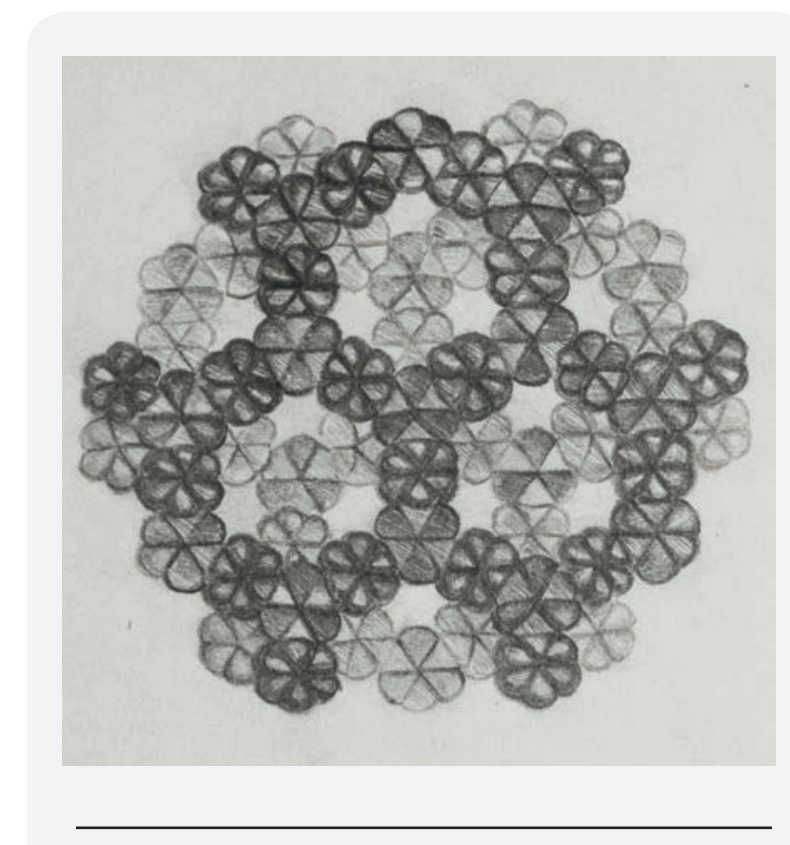

Fig. 7. Covalent organic framework-1 (COF-1) is an extended $2 D$ framework with staggered layers.

corresponding COFs crystallized using the same conditions or closely related ones to those mentioned earlier in this contributions ${ }^{43}$. The very first COF discovered was COF-1, which was made by dehydration of 1,4-benzene di-boronic acid to produce a staggered layered structure (Fig. 7). While the structure of the layers was easy to predict, since the monomer is planar, the stacking of the layers is more challenging. However, one can simulate the powder X-ray diffraction pattern for the eclipsed and the staggered stacking and match it to the experimentally found pattern and ultimately determine the stacking motif. Difficulties arise in almost all 2D COFs when the stacking is incommensurate and variations along the stacking axis make it difficult to refine the structure due to disorder problems ${ }^{20}$.

To achieve 3D frameworks, we used tetrahedral building units based on the same linkage (Fig. 8) ${ }^{21}$. In reticular chemistry, such a structure is a combination of linking tetrahedra with triangles, and based on our thesis of high symmetry, there are two possible net topologies for the COFs these shapes will produce. It is very common that in the reticular chemistry of MOFs and COFs, the metric information (angles between and within the linking units) provided by the starting building molecules represent a key control over directing the reticular synthesis to give a specific net topology ${ }^{43}$. At present, hundreds of 2D and 3D COFs have been thus synthesized and studied.

Linkage Conversion: This is a strategy for making COFs from less reversible linkages and therefore are much harder 


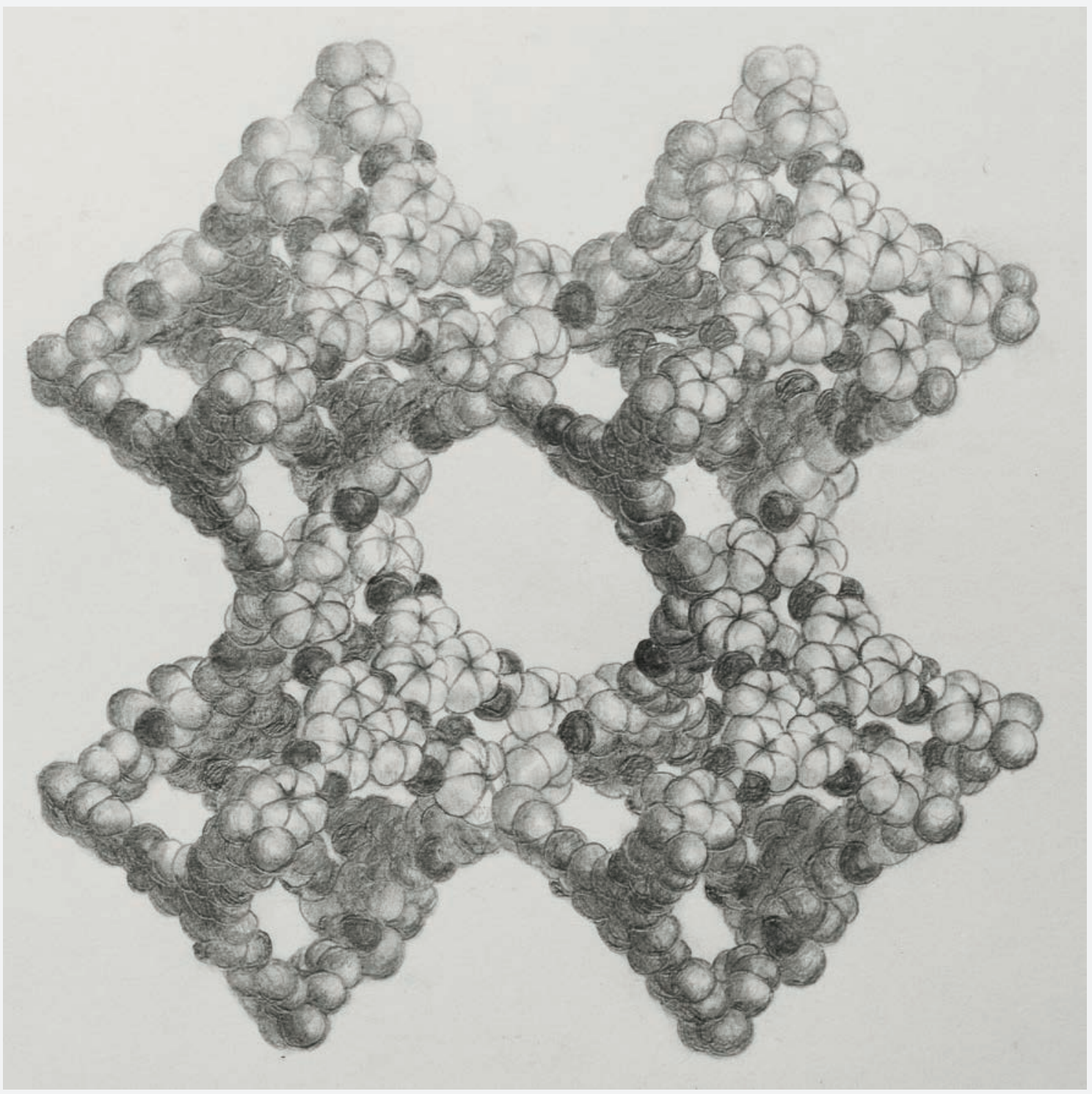

Fig. 8. COF-108 has an extended 3D structure and it is the least dense crystal known to date.

to crystallize. Here, a COF of a well-studied linkage and which is known to crystallize is used as a starting material. This is how this chemistry worked: We have attempted to make COFs based on amide linkages in the same way described above (de Novo) and found that they are not amenable to crystallization because they are considered less reversible linkages. Thus, we used an imine COF as the starting point and carried out oxidation reactions in a solid-to-solid transformation. $X$-ray powder diffraction, porosity, and spectroscopic data, all confirmed the conversion of imines to amides with full retention of crystallinity and without significant loss of porosity. This linkage-to-linkage conversion was later applied to make heterocyclic linkages and has been generalized in the chemistry of $\mathrm{COFs}^{44,45}$. The ability to convert hundreds of thousands of linkages in a solid granule of COF is indeed amazing. It speaks to the power of COFs in taking the precision of molecular chemistry to the solid state.

Another strategy, although not strictly linkage conversion, is to bring the reacting groups for a given linkage in a locked configuration as to minimize any side reactions and allow targeting of that specific linkage. For example, recently we showed that a least reversible dioxin linkage is crystallizable de Novo by bringing together the reacting units making the linkage in locked constrained fashion, which is followed 


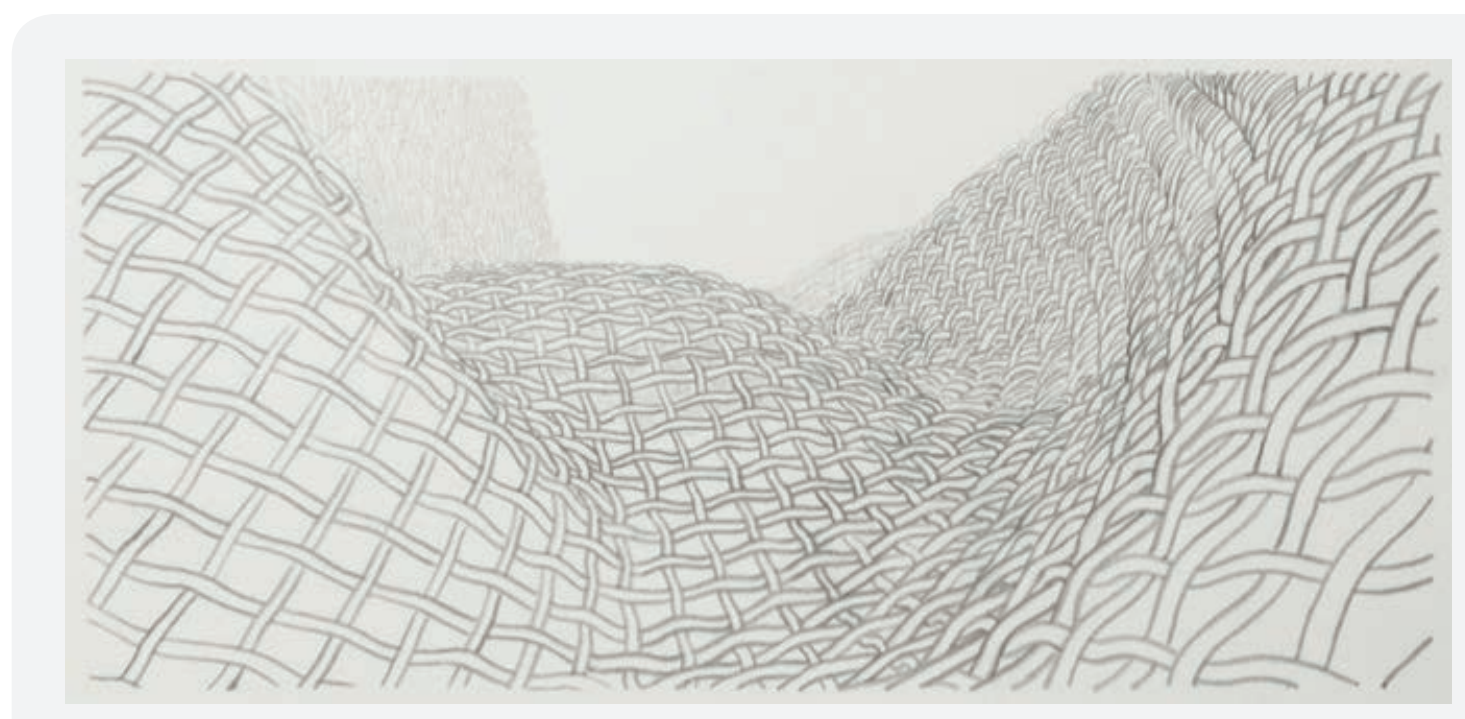

Fig. 9. Interlacing of threads (weaving).

by bond formation, thereby limiting the flexibility of the linkage and enhancing the crystallization process ${ }^{46}$.

Conversion of Carbon Dioxide in COFs: We aimed to demonstrate that the flexibility with which organic molecules can be functionalized is directly applicable to COF catalyst materials, and allows for dialing-in the electronic properties of the catalyst active site. We have demonstrated this using the electrocatalytic conversion of carbon dioxide to carbon monoxide. The molecular cobalt porphyrin catalysts was reticulated to make layered porous COF structures. The electrocatalytic activity of this COF for conversion of carbon dioxide to carbon monoxide far exceeds the molecular catalyst and also many of the heterogenous precious metal catalysts. The fact that the catalytic sites are distributed throughout the structure, makes them easily accessible to carbon dioxide. The covalent attachment of the catalyst within the backbone of the COF gives it an extra stability and blocks the usual deactivation mechanisms that often found for molecular catalysts ${ }^{47}$. And more to the point, we later observed that functionalizing the linkers joining the porphyrin catalysts in this COF results in optimizing the electronic character of the cobalt sites, providing for an eight-fold increase in catalytic activity. In other words, the covalently linked catalyst is also electronically 'wired' into the $\mathrm{COF}^{48}$.

Molecular Weaving: Thus far, we have focused our attention to making rigid frameworks for crystallinity but also for achieving shape-selective binding of guests. However, especially in catalysis, flexibility and dynamics are highly desirable in a catalyst. The question we considered is the following: How do we maintain the robustness of COFs but provide for dynamics and resiliency? We took our lesson from clothing. They are flexible yet resilient. The next question was: Can we make frameworks that are like fabrics? Indeed, the oldest method of making fabric is weaving, which is defined as the interlacing of threads to make $2 \mathrm{D}$ and $3 \mathrm{D}$ structures (Fig. 9). We recognized that weaving on the molecular level has the potential of combining the robustness, porosity and chemical versatility of COFs, with the dynamics and resiliency of woven structures. Since the threads have many degrees of freedom to have large amplitude motions, without being unzipped, dynamics can take place without stressing or breaking covalent bonds. We succeeded in making the first molecularly woven structures ${ }^{49}$. Our strategy was to make a mutually embracing copper (I) phenanthroline complex, often used to make the well-known catenanes, and functionalize its termini with aldehydes, then link these with diamines using $\mathrm{COF}$ chemistry to make imines. The copper ions serve to bring together the resulting threads at regular intervals and therefore aid in the crystallization of the COF. Once the metalated $\mathrm{COF}$ is formed and isolated, the copper ions can be removed by reaction with potassium cyanide to make the completely demetalated structure, which in turn is molecular weaving of imine threads (Fig. 10). The process of metalating and demetalating woven COFs is reversible and can be repeated without destruction or unzipping of the threads. We find that the woven structure is ten-fold more flexible compared to its metalated form.

We have since reported several other molecular weavings including a structure based on porous square ribbons and showed how these weavings are highly flexible and 


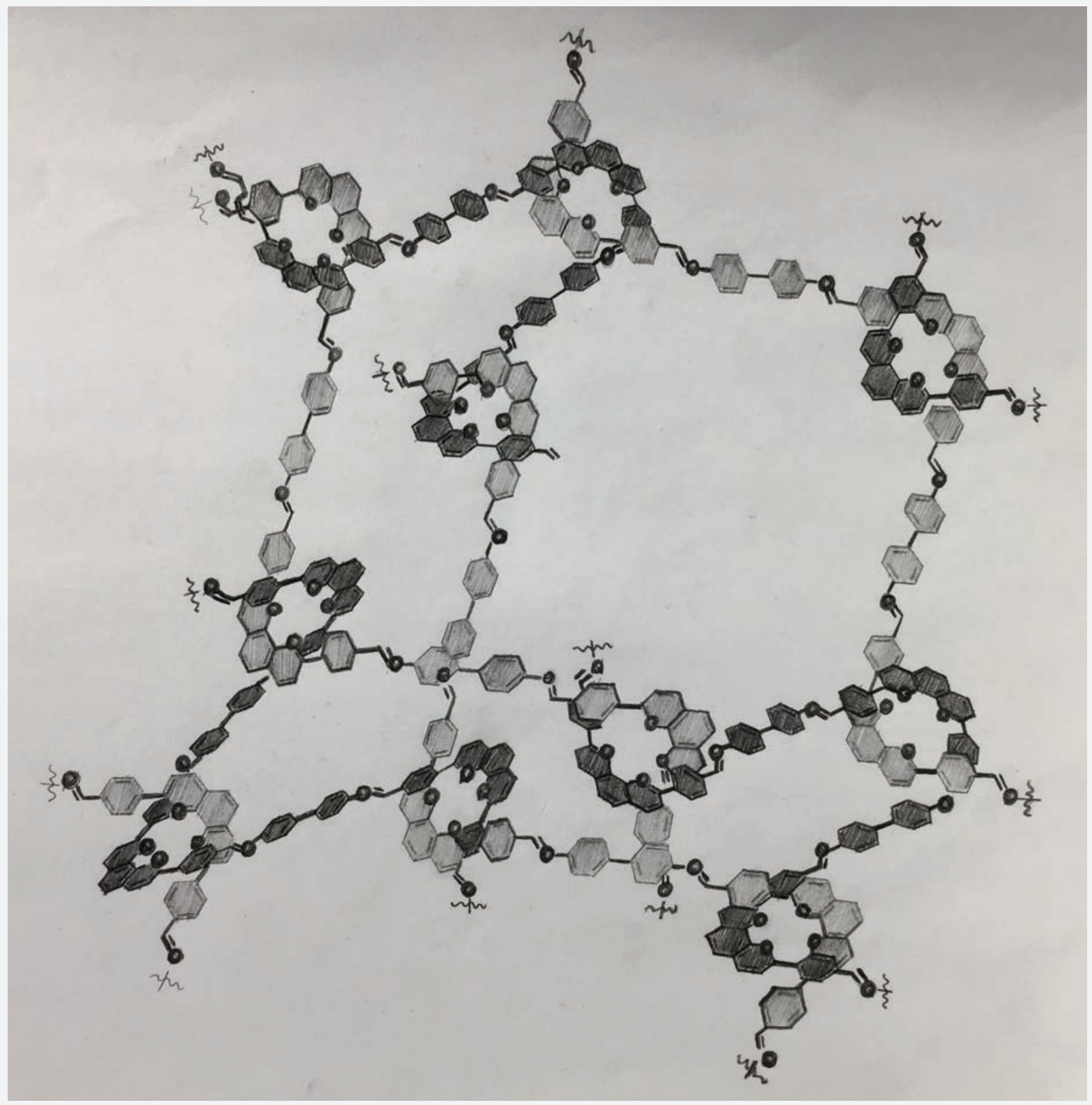

Fig. 10. Molecularly woven COF-505.

capable of adaptive inclusion ${ }^{50}$. Very large dye molecules, which exceed in size the pore opening of the metalated COF, were found to pass through once the $\mathrm{COF}$ is demetalated. Molecular weaving is considered the next generation advance in COFs as it leads to dynamic yet resilient structures. We believe that vast chemistry space exists where molecular weaving is the essential tool for combining the development of the covalent bond with the mechanical bond. Currently, we and collaborators are enumerating this new structure space. It is suffice to say that for the almost infinite number of net topologies available to reticular chemistry, molecular weaving parallels are potentially accessible to synthesis ${ }^{51}$. This has become a new and rich field of research.

\section{SECTION 5: CONCLUDING REMARKS AND FUTURE PROSPECTS}

From Molecules to Frameworks to Crystals: As presented already, reticular chemistry is the control of the strong bond, both metal-organic bonds to make MOFs and covalent bonds to make COFs. It is now common place to design and make 


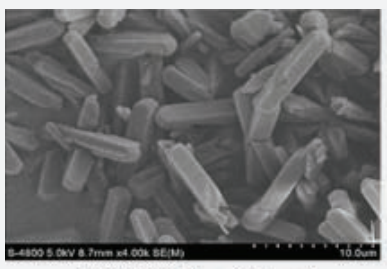

$\mathrm{COF}-303$ (ca. $15 \mu \mathrm{m})$

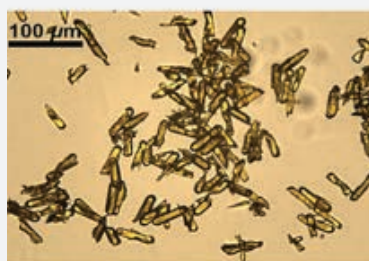

hydrated COF 300 (ca. $80 \mu \mathrm{m}$ )

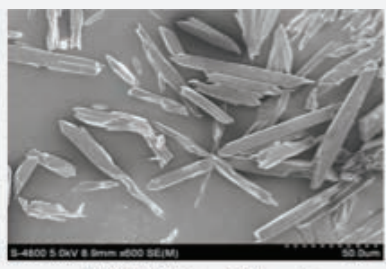

LZU-79 (ca. $100 \mu \mathrm{m})$

$50 \mathrm{jm}$

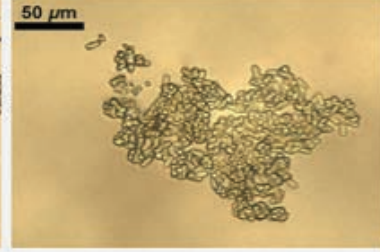

COF 303 (ca. $15 \mu \mathrm{m})$

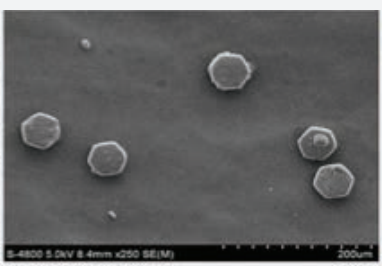

LZU-111 (ca. $50 \mu \mathrm{m}$ )

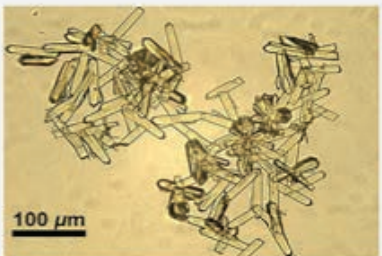

LZU-79 (ca. $100 \mu \mathrm{m}$ )

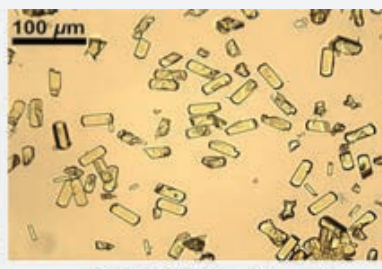

COF 300 (ca. $60 \mu \mathrm{m})$

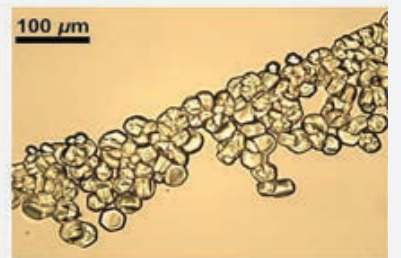

LZU-111 (ca. $50 \mu \mathrm{m}$ )

Fig. 11. Large single crystals of COFs have allowed characterization of COFs on the atomic level with the same precision routinely practiced in small molecule crystallography.

MOFs and COFs, which not only have architectural stability but also thermal and chemical stability. MOFs and COFs are stable up to $300-400^{\circ} \mathrm{C}$ in air, and many structures are stable in acid, base, aqueous and non-aqueous media, often at refluxing temperatures. The molecular definition of these frameworks has led to the development of their chemistry and also to the study of reactions within their pores. Although MOFs are routinely made as single crystalline, and therefore the chemistry benefits greatly from the precision of their atomic structures, COFs are routinely obtained as microcrystalline solids and characterized by powder X-ray diffraction techniques. Fortunately, a recent development has been to use aniline as a modulator to produce, for the first time, single crystals of COFs amenable to study of single crystal X-ray diffraction techniques (Fig. 11) ${ }^{52}$. This advance brings COF chemistry and the precision of their structure into the realm of molecular chemistry. In many ways, the idea of the 'atom and the molecule' which G. N. Lewis articulated in his original 1916 article and which has led to the well-known electron dot structures has now been extended to framework and thus 'the atom, the molecule, and the framework' sequence of development (Fig. 12).

Multivariable MOF and COF Structures: At present, a reticular chemist is adept to design and synthesis of the backbone of a MOF or COF, and with little effort. Because of the stability of these frameworks, their pores can be functionalized for a specific operation. This is leading to many applications in areas of clean energy, environment, sustainability and health. At this juncture, I like to ask: What comes next? A lot! I like to focus on one aspect to show the immensity and the great promise of the future. We have been discussing ordered frameworks because we need them to be crystalline and therefore well-defined; a necessary aspect for developing their chemistry and applications with precision. If we didn't overcome the crystallization challenge, we wouldn't have created this chemistry. But let's face it, fun and functionality are enhanced with 'heterogeneity'. Not bulk heterogeneity but molecular heterogeneity, where a structure is made from a large number of different kind of building units, like proteins, or few building units coming together in a large number of ways, like DNA. How do we create such heterogeneity in MOFs and COFs without losing the very order we need to keep sanity? The answer is in creating multivariable structures ${ }^{53-55}$.

We made multivariate MOF systems from variously functionalized organic linkers in a de Novo fashion. We showed that eight different functionalities can be incorporated into the original structure of MOF- 5 to produce a multivariate pore structure. The ratios of the functionalities and their character are easily obtained from nuclear magnetic resonance studies, but the spatial arrangement of the functionalities is unknown. The fact that the distance between the functionality is known, due to the periodic nature of the backbone, allows us to make a rudimentary analogy to DNA. In DNA, the nucleotides are covalently bonded to a repeating sugar polyphosphate backbone, and it is the spatial arrangements of the nucleotide sequences that code for the synthesis of proteins. Similarly, the multivariate functionalities bound covalently to the repeating, ordered MOF backbone, may very well form sequences that eventually can be designed to code for specific functions. We have already found that the multivariate MOF-5 performs 4-folds better than 


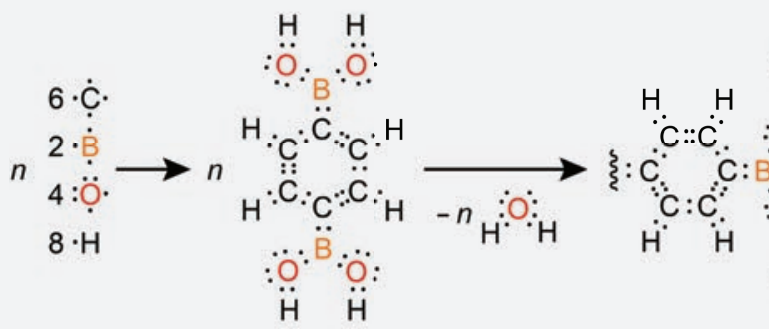

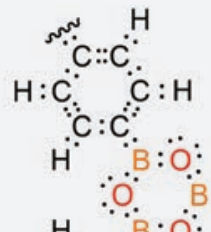<smiles></smiles>
:<smiles>[C+]1=CC=CC=[C+]1</smiles>

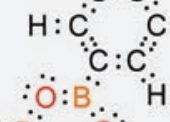<smiles>[C]1C=C[C]2C=C[C]1C2</smiles>
$\dot{H} \ddot{H}$<smiles>[CH]C[Se][Se]=[Se]</smiles>

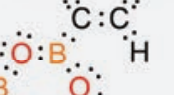<smiles>C1CCCCC1</smiles><smiles></smiles><smiles>[Ge]</smiles>

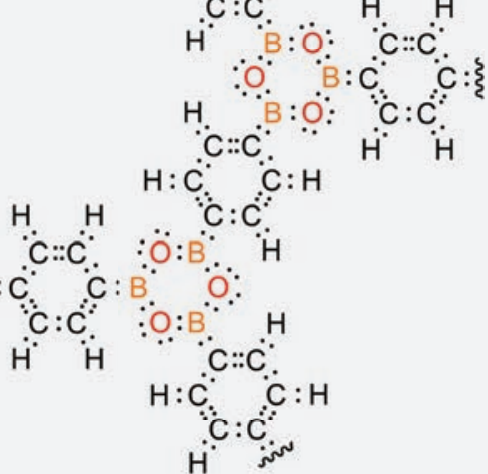

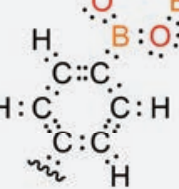

Framework

\begin{abstract}
Fig. 12. The atom, the molecule, and the covalent organic framework. This progression indicates how the molecule fixes atoms in specific geometry, connectivity, and spatial arrangement, and with reticular chemistry, the framework fixes molecules in specific geometry, connectivity, spatial arrangement. However, unlike the molecule, the framework encompasses space into which matter can be further manipulated and controlled.
\end{abstract}

the MOF-5 with only one functionality, and that the whole performs better than the sum of its parts ${ }^{53}$. We have been using solid-state nuclear magnetic resonance techniques to decipher these sequences ${ }^{54}$. The results of these studies confirm the multivariate nature of the functionality's spatial arrangements and that, depending on the functionalities in question, they arrange themselves in random, well-mixed, small domain, or large domain structures. In other words, order is preserved by virtue of the repeating backbone but heterogeneity is created by covalent attachment of functionalities to that backbone.

We wish to point out that when chemical reactions are performed on a functionality tethered onto the backbone of the framework (i.e. postsynthetic modification), inevitably a multivariate system is also produced. The fact that these reactions are not quantitative means that the interior of the pores would have converted and unconverted functionalities covalently bound to the backbone. This scenario automatically results in a combinatorial number of environments within the pores of a multivariate MOF. We have shown that in an expanded derivative of MOF-74, seven consecutive post-synthetic modifications are successfully applied to covalently attach a short peptide onto the backbone. Naturally, the resulting MOF was multivariate since these transformations are indeed non-quantitative, leaving behind a 'forest' of highly variable microenvironments. As it turns out it is the key for carrying out highly selective transformations. This was demonstrated for an amide bond cleavage reaction that is only realized by TEV protease enzyme. We find that when the pores of expanded MOF-74 are functionalized with the essential amino acids in the active site of this enzyme, the same selectivity of the enzyme is achieved by what we know is a multivariate $\mathrm{MOF}^{55}$. It is clear that heterogeneity being covalently attached to MOF backbone has the potential of enzyme-like reactions but under wider stability conditions than those enzymes. This opens a whole new direction for MOFs and in due course COFs as well, where crafting the interior leads to highly selective and specific chemical transformations.

On the basic science level, reticular chemistry and the control of the covalent bond has led to significant expansion of the wider field of chemistry, and has made available large classes of new functional structures. The ability to create 'heterogeneity within order' in these reticular structures further pushes the frontiers of chemistry toward the design of sequence dependent frameworks ${ }^{56}$. In the context of chemistry as a whole, reticular chemistry has taken the precision of molecular chemistry, and the flexibility with which it is applied to transform molecules, to 2D and 3D structures as demonstrated for MOFs and COFs. 


\section{ACKNOWLEDGEMENTS}

I wish to express my deep appreciation to all my graduate students and postdoctoral fellows whose innovative contributions (cited in this article, and some are pictured below) made the days interesting, the science fun, and the positive impact on society

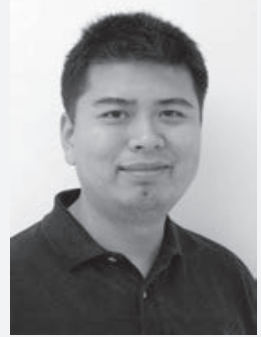

Qiaowei Li is currently a Professor of Chemistry at Fudan University, China. He received his Ph.D. degree in Chemistry from University of California, Los Angeles in 2010 under the supervision of Prof. Omar M. Yaghi. His current research includes the reticular chemistry of multicomponent MOFs and ordered vacancies in porous crystals. For more information: www.fudanchem.net. possible. Many of the structures in this contribution are 'classics' in the field of reticular chemistry and I thought it might be interesting to pencil sketch them as an 'art and science' experiment. Many thanks are in order to the joint effort of Prof. Qiaowei Li and Miss Yi Liu for the sketch drawings.
Miss Liu, $\mathrm{Yi}$ is an intermedia artist living in Hangzhou, China. She obtained her Master degree in Arts from the China Academy of Fine Arts in 2016. She deploys various mediums through animation, multi-media as well as space installation to reflect her daily living experience and discovers more possibilities in a space resonating with the subject of her works. For more information: www.liu-yi.com.

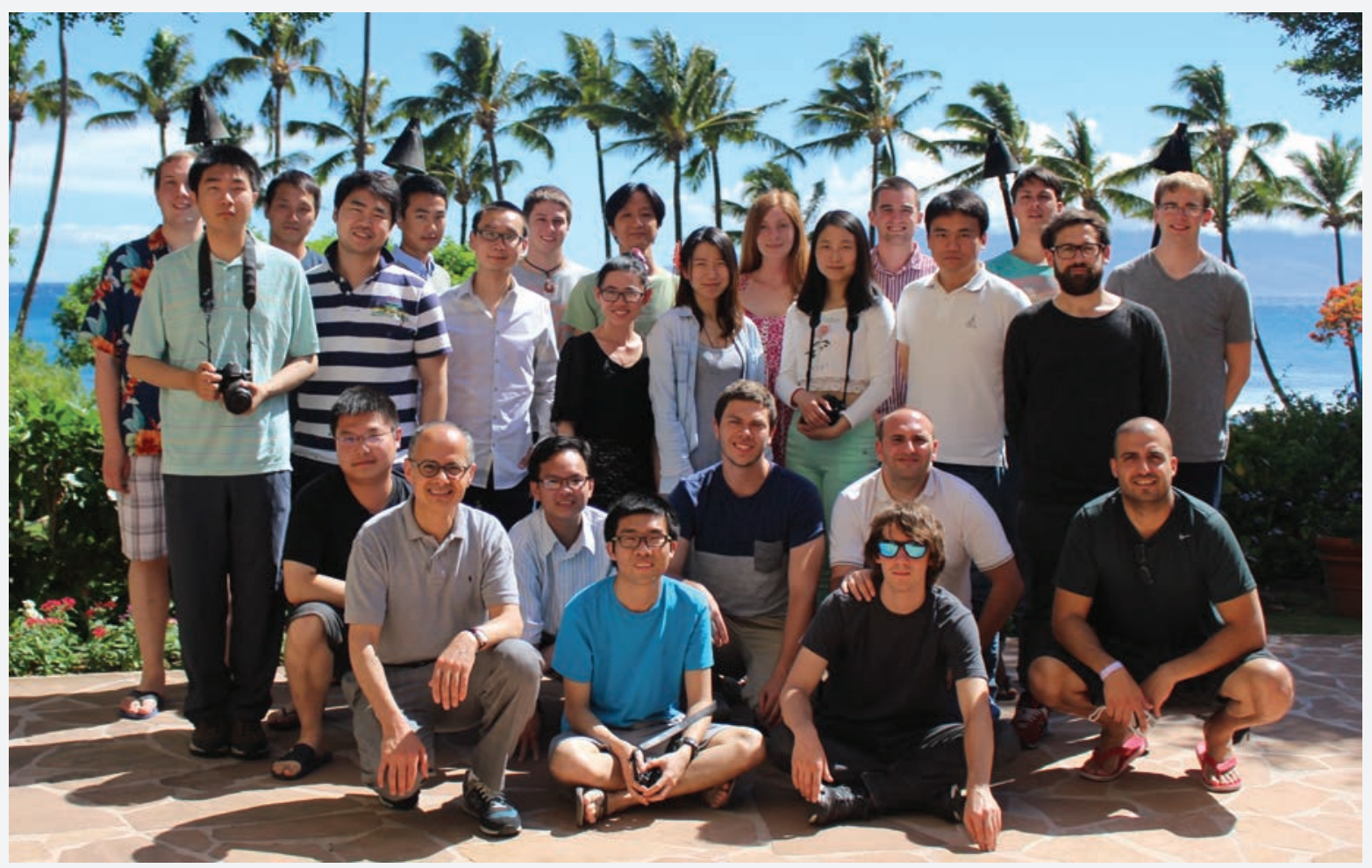

Yaghi group: back row, left to right in rows: Alex Schoedel (Germany), Seung Kyu Lee (S. Korea), Zhe Ji (China), Chris Trickett (U.K.), Hiroyasu Furukawa (Japan), Noelle Catarineu (U.S.), Robinson Flaig (U.S.), Eugene Kapustin (Ukraine), Peter Waller (U.S.), Yingbo Zhao (China), Hyung Mo Jeong (S. Korea), Jingjing Yang (China), Nhung Tuyet Thi Nguyen (Vietnam), Yuzhong Liu (China), Lei Guo (China), Kyungmin Choi (S. Korea), Philipp Urban (Germany), Juncong Jiang (China), Thach Ngoc Tu (Vietnam), Christian Diercks (Germany), Alejandro Fracaroli (Argentina), Peter Siman (Israel), Omar Yaghi (U.S. and Jordan), Bunyarat Rungtaweevoranit (Thailand), Steven Lyle (U.S.). 


\section{REFERENCES}

1. Werner, A. Beitrag zur konstitution anorganischer verbindungen. Z. Anorg. Allg. Chem. 3, 267-330 (1893).

2. Allison, S.A. \& Barrer, R.M. Sorption in the $\beta$-phases of transition metal(II) tetra-(4-methylpyridine)thiocyanates and related compounds. J. Chem. Soc. A Inorg. Phys. Theor. 0, 1717-1723 (1969), doi: 10.1039/ J19690001717.

3. Bailar, J.C., Jr. Coordination polymers. In: Preparative Inorganic Reactions (ed.) Jolly, W.L. (Interscience Publishers, Wiley, 1964), pp. 1-27.

4. Kinoshita, Y., Matsubara, I. \& Saito, Y. The crystal structure of bis(glutaronitrilo)copper(I) nitrate. Bull. Chem. Soc. Jpn. 32, 1216-1221 (1959).

5. Kinoshita, Y., Matsubara, I., Higuchi, T. \& Saito, Y. The crystal structure of bis(adiponitrilo)copper(l) nitrate. Bull. Chem. Soc. Jpn. 32(11), 1221-1226 (1959).

6. Aumüller, A., Erk, P., Klebe, G. et al. A radical anion salt of 2,5-dimethyl-N, $\mathrm{N}^{\prime}$-dicyanoquinonediimine with extremely high electrical conductivity. Angew. Chem. Int. Ed. Engl. 25, 740-741 (1986).

7. Hoskins, B.F. \& Robson, R. Infinite polymeric frameworks consisting of three dimensionally linked rod-like segments. J. Am. Chem. Soc. 111, 5962-5964 (1989).

8. Fujita, M., Yazaki, J. \& Ogura, K. Preparation of a macrocyclic polynuclear complex, $\left[(\mathrm{en}) \mathrm{Pd}\left(4,4^{\prime}-\mathrm{bpy}\right)\right]_{4}\left(\mathrm{NO}_{3}\right)_{8}$ (en = ethylenediamine, bpy = bipyridine), which recognizes an organic molecule in aqueous media. J. Am. Chem. Soc. 112, 5645-5647 (1990).

9. Zaworotko, M.J. Crystal engineering of diamondoid networks. Chem. Soc. Rev. 23(4), 283-288 (1994).

10. Yaghi, 0. \& Li, H. Hydrothermal synthesis of a metalorganic framework containing large rectangular channels. J. Am. Chem. Soc. 117, 10401-10402 (1995).

11. Stahl, G.E. Experimenta, observationes, animadversions. In: Chymicae et Physicae, Berlin, pp. 281-283 (1731).

12. Hofmann, K. \& Küspert, F. Verbindungen von kohlenwasserstoffen mit metallsalzen. Z. Anorg. Allg. Chem. 15, 204-207 (1897).

13. Li, H., Eddaoudi, M., Groy, T.L. \& Yaghi, O.M. Establishing microporosity in open metal-organic frameworks: gas sorption isotherms for $\mathrm{Zn}(\mathrm{BDC})$ (BDC = 1,4-benzenedicarboxylate). J. Am. Chem. Soc. 120, 8571-8572 (1998).

14. Li, H., Eddaoudi, M., O'Keeffe, M. \& Yaghi, O.M. Design and synthesis of an exceptionally stable and highly porous metal-organic framework. Nature 402, 276 (1999).

15. Eddaoudi, M., Moler, D., Li, H., Reineke, T.M., O'Keeffe, M. \& Yaghi, O.M. Modular chemistry: secondary building units as a basis for the design of highly porous and robust metal-organic carboxylate frameworks. Acc. Chem. Res. 34, 319-330 (2001).

16. Rowsell, J.L.C., Spenser, E.C., Eckert, J., Howard, J.A.K. \& Yaghi 0.M. Gas adsorption sites in a large-pore metalorganic framework. Science 309, 1350-1354 (2005).

17. Yaghi, O.M., O'Keeffe, M., Ockwig, N.W., Chae, H.K., Eddaoudi, M. \& Kim, J. Reticular synthesis and the design of new materials. Nature 423, 705-714 (2003).

18. Lewis, G.N. The atom and the molecule. J. Am. Chem. Soc. 38, 762 (1916).

19. Hoffmann, R. How should chemists think? Sci. Am. 268, 66-73 (February 1993).

20. Côté, A.P., Benin, A.l., Ockwig, N.W., Matzger, A.J., O'Keeffe, M. \& Yaghi, 0.M. Porous, crystalline, covalent organic frameworks. Science 310, 1166-117 (2005).

21. El-Kaderi, H.M., Hunt, J.R., Mendoza-Cortés, J.L., Côté, A.P., Taylor, R.E., O'Keeffe, M. \& Yaghi, 0.M. Designed synthesis of 3D covalent organic frameworks. Science 316, 268-272 (2007).

22. Furukawa, H., Cordova, K.E., O'Keeffe, M. \& Yaghi, $0 . M$. The chemistry and applications of metal-organic frameworks. Science 341, 1230444 (2013).

23. Wells, A.F. Structural Inorganic Chemistry, $5^{\text {th }}$ Ed. (0xford Science Publications, 1984).

24. O'Keeffe, M., Peskov, M.A., Ramsden, S.J. \& Yaghi, 0.M. The reticular chemistry structure resource (RCSR) database of, and symbols for, crystal nets. Acc. Chem. Res. 41, 1782-1789 (2008).

25. RCSR database at http://rcsr.anu.edu.au

26. Delgado-Friedrichs, 0., Foster, M.D., O'Keeffe, M., Prosperio, D.M., Treacy, M. \& Yaghi, O.M. What do we know about three-periodic nets? J. Solid State Chem. 178, 2533-2554 (2005).

27. Eddaoudi, M., Kim, J., Rosi, N.L., Vodak, D.T., Wachter, J., O'Keeffe, M. \& Yaghi, 0.M. Systematic design of pore size and functionality in isoreticular metal-organic frameworks and application in methane storage. Science 295, 469-472 (2002).

28. Deng, H., Grunder, S., Cordova, K.E., Valente, C., Furukawa, H., Hmadeh, M., Gándara, F., Whalley, A.C., Liu, Z., Asahina, S., Kazumori, H., O'Keeffe, M., Terasaki, 0., Stoddart, J.F. \& Yaghi, 0.M. Large-pore apertures in a series of metal-organic frameworks. Science 336, 1018-1023 (2012).

29. Chen, B., Eddaoudi, M., Reineke, T.M., Kampf, J.W., 0.Keeffe, M. \& Yaghi, 0. M. $\mathrm{Cu}_{2}(\mathrm{ATC}) \cdot 6 \mathrm{H}_{2} \mathrm{O}$ : Design of open metal sites in porous metal-organic crystals (ATC: 1,3,5,7-adamantane tetracarboxylate). J. Am. Chem. Soc. 122, 11559-11560 (2000).

30. Baek, J., Rungtaweevoranit, B., Pei, X., Park, M., Fakra, S.C., Liu, Y., Matheu, R., Alshmimri, S.A., Alshehri, S., 
Trickett, C.A., Somorjai, G.A. \& Yaghi, 0.M. Bioinspired metal-organic framework catalysts for selective methane oxidation to methanol. J. Am. Chem. Soc. 140, 18208-18216 (2018).

31. Tu, B., Pang, Q., Wu, D., Song, Y., Weng, L. \& Li, Q. Ordered vacancies and their chemistry in metal-organic frameworks. J. Am. Chem. Soc. 136, 14465-14471 (2014).

32. Wang, Z. \& Cohen, S.M. Postsynthetic covalent modification of a neutral metal-organic framework. J. Am. Chem. Soc. 129, 12368-12369 (2007).

33. Morris, W., Doonan, C.J., Furukawa, H., Banerjee, R. \& Yaghi, 0.M. Crystals as molecules: postsynthesis covalent functionalization of zeolitic imidazolate frameworks. J. Am. Chem. Soc. 130, 12626-12627 (2008).

34. Mueller, U., Schubert, M., Teich, F., Puetter, H., Schierle-Arndt, K. \& Pastré, J. Metal-organic frameworksperspective industrial applications. J. Mater. Chem. 16, 626-636 (2006).

35. Britt, D., Furukawa, H., Wang, B., Glover, T.G. \& Yaghi, 0.M. Highly efficient separation of carbon dioxide by a metal-organic framework replete with open metal sites. Proc. Natl. Acad. Sci. U.S.A. 106, 20637-20640 (2009).

36. Fracaroli, A.M., Furukawa, H., Suzuki, M., Dodd, M., Okajima, S., Gándara, F., Reimer, J.A. \& Yaghi, 0.M. Metalorganic frameworks with precisely designed interior for carbon dioxide capture in the presence of water. J. Am. Chem. Soc. 136, 8863-8866 (2014).

37. Flaig, R.W., Osborn Popp, T.M., Fracaroli, A.M., Kapustin, E.A., Kalmutzki, M.J., Altamimi, M.R., Fathieh, F., Reimer, J.A. \& Yaghi, O.M. The chemistry of $\mathrm{CO}_{2}$ capture in an amine-functionalized metal-organic framework under dry and humid conditions. J. Am. Chem. Soc. 139, 12125-12128 (2017).

38. Nguyen, N.T.T., Furukawa, H., Gándara, F., Nguyen, H.T., Cordova, K.E. \& Yaghi, 0.M., Selective capture of carbon dioxide under humid conditions by hydrophobic chabazite-type zeolitic imidazolate frameworks. Angew. Chem. Int. Ed. 53, 10645-10648 (2014).

39. Furukawa, H., Gándara, F., Zhang, Y.-B., Jiang, J., Queen, W.L., Hudson, M.R. \& Yaghi, O.M. Water adsorption in porous metal-organic frameworks and related materials. J. Am. Chem. Soc. 136, 4369-4381 (2014).

40. Kim, H., Yang, S., Rao, S.R., Narayanan, S., Kapustin, E.A., Furukawa, H., Umans, A.S., Yaghi, O.M. \& Wang, E.N. Water harvesting from air with metal-organic frameworks powered by natural sunlight. Science $\mathbf{3 5 6}$, 430-434 (2017).

41. Kim, H., Rao, S.R., Kapustin, E.A., Zhao, L., Yang, S., Yaghi, 0.M. \& Wang, E.N. Adsorption-based atmospheric water harvesting device for arid climates. Nat. Commun. 9, 1191 (2018).
42. Fathieh, F., Kalmutzki, M.J., Kapustin, E.A., Waller, P.J., Yang, J. \& Yaghi, 0.M. Practical water production from desert air. Sci. Adv. 4, eaat3198 (2018).

43. Diercks, C.S. \& Yaghi, O.M. The atom, the molecule, and the covalent organic framework. Science 355, 923 (2017).

44. Waller, P.J., Lyle, S., Osborn Popp, T., Diercks, C.S., Reimer, J.A. \& Yaghi, O.M. Chemical conversion of linkages in covalent organic frameworks. J. Am. Chem. Soc. 138, 15519-15522 (2016).

45. Waller, P.J., AlFaraj, Y.S., Diercks, C.S., Jarenwattananon, N.N. \& Yaghi, O.M. Conversion of imine to oxazole and thiazole linkages in covalent organic frameworks. J. Am. Chem. Soc. 140, 9099-9103 (2018).

46. Zhang, B., Wei, M., Mao, H., Pei, X., Alshmimri, S.A., Reimer, J.A. \& Yaghi, O.M. Crystalline dioxin-linked covalent organic frameworks from irreversible reactions. J. Am. Chem. Soc. 140, 12715-12719 (2018).

47. Lin, S., Diercks, C.S., Zhang, Y.-B., Kornienko, N., Nichols, E.M., Zhao, Y., Paris, A.R., Kim, D., Yang, P., Yaghi, O.M. \& Chang, C.J. Covalent organic frameworks comprising cobalt porphyrins for catalytic $\mathrm{CO}_{2}$ reduction in water. Science 349, 1208-1213 (2015).

48. Diercks, C.S., Lin, S., Kornienko, N., Kapustin, E.A., Nichols, E.M., Zhu, C., Zhao, Y., Chang, C.J. \& Yaghi, O.M. Reticular electronic tuning of porphyrin active sites in covalent organic frameworks for electrocatalytic carbon dioxide reduction. J. Am. Chem. Soc. 140, 1116-1122 (2018).

49. Liu, Y., Ma, Y., Zhao, Y., Sun, X., Gándara, F., Furukawa, H., Liu, Z., Zhu, H., Zhu, C., Suenaga, K., Oleynikov, P., Alshammari, A.S., Zhang, X., Terasaki, O. \& Yaghi, O.M. Weaving of organic threads into a crystalline covalent organic framework. Science 351, 365-369 (2016).

50. Liu, Y., Ma, Y., Yang, J., Diercks, C.S., Tamura, N., Jin, F. \& Yaghi, 0.M. Molecular weaving of covalent organic frameworks for adaptive guest inclusion. J. Am. Chem. Soc. 140, 16015-16019 (2018).

51. Liu, Y., O'Keeffe, M., Treacy, M.M.J. \& Yaghi, 0.M. The geometry of periodic knots, polycatenanes and weaving from a chemical perspective: a library for reticular chemistry. Chem. Soc. Rev. 47, 4642-4664 (2018).

52. Kapustin, E.A., Yin, S.X., Liang, L., Zhou, Z., Niu, J., Li, L., Wang, Y., Su, J., Li, J., Wang, X., Wang, W.D., Wang, W., Sun, J. \& Yaghi, O.M. Single-crystal X-ray diffraction structures of covalent organic frameworks. Science 361, 48-52 (2018).

53. Deng, H., Doonan, C.J., Furukawa, H., Ferreira, R.B., Towne, J., Knobler, C.B., Wang, B. \& Yaghi, O.M. Multiple functional groups of varying ratios in metal-organic frameworks. Science 327, 846-850 (2010). 
54. Kong, X., Deng, H., Yan, F., Kim, J., Swisher, J.A., Smit, B., Yaghi, 0.M. \& Reimer, J.A. Mapping of functional groups in metal-organic frameworks. Science 341, 882-885 (2013).

55. Fracaroli, A., Siman, P., Nagib, D., Suzuki, M., Furukawa, H., Toste, F.D. \& Yaghi, O.M. Seven post-synthetic covalent reactions in tandem leading to enzyme-like complexity within metal-organic framework crystals. J. Am. Chem. Soc. 138, 8352-8355 (2016).

56. Furukawa, H., Müller, U. \& Yaghi, O.M. "Heterogeneity within order" in metal-organic frameworks. Angew. Chem. Int. Ed. 54, 3417-3430 (2015). 